\title{
THE ROLE OF IMMIGRATION IN DEALING WITH THE DEVELOPED WORLD'S DEMOGRAPHIC TRANSITION
}

\author{
Hans Fehr \\ Sabine Jokisch \\ Laurence Kotlikoff \\ Working Paper 10512 \\ http://www.nber.org/papers/w10512
NATIONAL BUREAU OF ECONOMIC RESEARCH 1050 Massachusetts Avenue
Cambridge, MA 02138 \\ May 2004
}

The views expressed herein are those of the author(s) and not necessarily those of the National Bureau of Economic Research.

(C2004 by Hans Fehr, Sabine Jokisch, and Laurence Kotlikoff. All rights reserved. Short sections of text, not to exceed two paragraphs, may be quoted without explicit permission provided that full credit, including (C) notice, is given to the source. 
The Role of Immigration in Dealing with the Developed World's Demographic Transition Hans Fehr, Sabine Jokisch, and Laurence Kotlikoff

NBER Working Paper No. 10512

May 2004

JEL No. E62, H5, H6

ABSTRACT

This paper and its companion study, Fehr, Jokisch, and Kotlikoff (2004), develop a three-region dynamic general equilibrium life-cycle model to analyze general and skill-specific immigration policy during the demographic transition. The three regions are the U.S., Japan, and the EU. Immigration is often offered as a solution to the remarkable again underway in the developed world. Absent an immediate and dramatic change in immigration, dependency ratios will roughly double over the next three decades placing fiscal institutions, in particular, and economies, in general, under enormous stress.

Can immigration alleviate these stresses? The answer is unclear bacause a number of offsetting factors are at play. First, increased immigration raises the size of the labor force, but also lowers real wages. Hence, the increase in the taxable wage base due to immigration will be less than might otherwise be expected. Second, immigrants arrive with some capital and accumulate more capital as they age. This raises labor productivity and both payroll and income tax bases. Third, immigrants, like natives, require public goods and become eligible for government welfare, health care, and pension benefits.

Fiscally speaking, how much one "earns" from a new immigrant depends on the immigant's skill level, which, in turn, determines the immigrant's level of earnings. The reason is that taxes and transfer payments are, in general, collected and distributed on a progressive basis. Consequently, high-skilled immigrants deliver a larger bang for the buck when it comes to paying net taxes (taxes paid net of transfer payments received).

Our model confirms this point. Nonetheless, its findings, even with respect to high-skilled immigration, which we investigate in detail in this paper, are not pretty. It shows that a significant expansion of immigration, whether across all skill groups or among particular skill groups, will do remarkably little to alter the major capital shortage, tax hikes, and reductions in real wages that can be expected along the demographic transition.

\author{
Hans Fehr \\ University of Wuerzburg \\ Sabine Jokisch \\ University of Wuerzburg \\ Laurence Kotlikoff \\ Department of Economics \\ Boston University \\ 270 Bay State Road \\ Boston, MA 02215 \\ and NBER \\ kotlikof@bu.edu
}




\section{Introduction}

Thanks to decades of low birth rates and rising life expectancies, virtually the entire developed world is in the process of dramatically aging. In the euro area, for example, the dependency ratio - the ratio of those aged 65 and over to those aged 15 to 65 - will more than double by 2040. Given that governments generally finance the payment of pension and health care benefits to the elderly by taxing workers, the prospects of much older societies suggests a tremendous fiscal crisis. This is the well-known bad news about the economics of aging. The question raised here is whether there is some offsetting good news associated with the aging process. One possible source is capital deepening arising from a rise in the number of elderly asset holders (suppliers of capital) relative to the number of workers (suppliers of labor). A second alleged source of economic salvation is expanding immigration.

This paper as well as a companion article, Fehr, Jokisch, and Kotlikoff (2004), upon which this paper draws, explore both of these potential cures for the developed world's demographic woes. Fehr, Jokisch, and Kotlikoff (2004) introduced our model and showed the effects of a simultaneous doubling of immigration among all skill groups in all three regions. The current paper considers skill-specific as well as region-specific expansions of immigration.

The framework for our analysis is a three-region dynamic overlapping generations general equilibrium life-cycle model. The three regions are the U.S., Japan, and the EU. There is a single good that can either be consumed or invested at home or abroad; i.e., there is international capital mobility. In contrast to capital, labor is not mobile internationally, and immigration to each region is exogenous.

To preview our conclusions, we find that both cures - capital deepening and increased immigration - are fake elixirs. Indeed, instead of capital deepening, the developed world can look forward to a significant capital shortage that will reduce real wages by one fifth and raise real interest rates by one half. While there will be more elderly owning and supplying capital compared to the number of young and middle-aged workers supplying labor, average growthadjusted capital holdings per oldster will decline over time. The reason is simple - the huge 
increase in taxes needed along the demographic transition to cover benefit obligations to the elderly will greatly limit the claims to capital that successive generations bring into retirement.

In the case of immigration, our results suggest a double-edged sword. On the one hand, more immigrants increase the number of workers and, therefore, the taxable wage base. On the other hand, more immigrants, particularly low skilled immigrants, demand public goods as well as transfer payments, neither of which is cheap. According to our model, the costs of additional immigrants, assuming they have the same distribution of skills as the current immigrants, roughly equal the revenue gains they engender. On balance, such a uniform expansion of immigration makes essentially no difference to the developed world's demographic transition path. On the other hand, if immigration is expanded primarily among the low skilled, fiscal conditions will significantly deteriorate. The opposite is true in the case of expanding immigration among the high skilled. Unfortunately, materially improving the developed world's future economic prospects would require massive increases in high-skilled immigrants, all of whom would have to come from the developing world.

Our paper begins by reviewing the literature and describing the demographic transition and the structure of the simulation model. Next we discuss the calibration and the baseline transition path of the economy, which keeps current immigration constant. Then, we quantify the macroeconomic and welfare effects of alternative unilateral and multilateral immigration policies.

\section{Literature Review}

Our model's closest relative is Kotlikoff, Smetters, and Walliser (2001), which itself descends from the Auerbach-Kotlikoff's (1987) overlapping generation (OLG) model. Like the former model, ours examines the demographic transition and incorporates age-specific fertility, lifespan extension, intergenerational earnings heterogeneity, and a range of fiscal institutions. But unlike that study, this one includes international capital mobility, lifespan uncertainty, bequests arising from incomplete annuitization, capital adjustment costs, and immigration, which can be either uniform or skill-specific. 
Demographic transitions in developed countries have generally been analyzed in closed economy models that ignore immigration and, obviously, international capital mobility. More recent studies have begun to introduce these elements. The French INGENUE (2002) team divides the world into six large regions - three developed areas and three developing areas each of which has quite different demographics. The team reports a small degree of capital deepening along the global demographic transition. Boersch-Supan, et. al. (2002) set up a three-region OLG model, featuring Germany, Europe, and the rest of the OECD, to examine the international ramifications of alternative German pension reforms. They also find very little change in the capital-labor ratio in their open economy simulations. And Brooks (2003) simulates the general equilibrium effects of past and current population trends on capital flows within a model that features eight regions. He finds that differences in population trends were important determinants of international capital flows in the past and predicts that they will be as important in the future.

Each of these general equilibrium studies omits immigration as a policy instrument. However, immigration has been addressed in both partial and general equilibrium. Auerbach and Oreopoulos (1999) and Bonin, et. al. (2000) use generational accounting - a partial equilibrium framework - to quantify the fiscal implications of immigration in the U.S. and Germany, respectively. The U.S. study finds relatively small fiscal effects of expanding immigration, whereas the German study finds significant effects.

Lundborg and Segerstrom (2002) and Storeletten (2000) provide general equilibrium treatments of immigration. Lundborg and Segerstrom (2002) develop a two-country version of the endogenous growth model with quality ladders. In their simulations, immigration from the low-tech (South) to the high-tech (North) country enhances growth in both countries, but reduces wages in the destination country. Consequently, native workers in the North lose while immigrants from the south gain. Due to faster growth, more firms are driven out of business, which in turn reduces the stock market value of firms and hurts capital owners. Since Lundborg and Segerstrom (2002) apply a stylized infinitely lived-agent model, their study ignores the age and skill composition of immigrants. 
Such aspects are considered in Storesletten (2000) who investigates the fiscal effects of immigration policies in the U.S. within an extended Auerbach and Kotlikoff (1987) model that has broadly similar features to our own. The differences between the two models are, however, important and may help explain our somewhat different findings. In our model, but not in Storesletten's, immigrants enter the country with asset holdings that are the same as those of natives of the same age and skill level. Our model also features age-specific inheritances, whereas Storesletten assumes that only young adults receive inheritances. Third, our model features age-specific fertility, which we view as critically important to generate a realistic population age-distributions through time. Fourth, our model takes a period to be a single year, whereas Storesletten treats a period as five years. Fifth, Storesletten focuses on increasing high-skilled immigrants in a very narrow age range, whereas we consider increasing high-skilled immigrants at all ages. Sixth, our model treats the U.S. as an open economy and captures international spillovers from multilateral and unilateral changes in immigration policy.

Despite their differences, both studies reach the same bottom line with respect to a uniform expansion of immigration, namely that it will do little to improve the dire fiscal finances of the United States. Both studies also agree that increasing the number of high-skilled immigrants can be beneficial. However, according to our model, even a doubling of high skilled immigrants would still leave the developed world with a major fiscal crisis in its hands.

While increasing skilled immigration sounds easy, this is not likely to be the case. The reason is that most skilled workers live in the U.S., the EU, and Japan. Moving a high skilled worker from one of these regions to another is a zero-sum game. The alternative - luring high skilled workers from developing countries to the developed world - will greatly exacerbate the brain drain that is already greatly depleting the human capital of developing countries.

\section{Modelling the World Economy ${ }^{1}$}

Like other dynamic life-cycle models featuring fertility, our model features monozygotic reproduction. But to achieve a realistic pattern of births by age, we follow Kotlikoff, et al.

\footnotetext{
${ }^{1}$ This section draws heavily on Fehr, Jokisch and Kotlikoff (2004).
} 
(2001) in assuming that agents in their child-bearing years give birth each year to fractions of children. As a consequence, each agent's household size and structure is changing over the life-cycle. Since agents in our model care about their children's utility when they are young and spend more on consumption when their kids are at home, our model delivers a rise in the longitudinal age-consumption profile during child-rearing years. In addition, by specifying how age-specific fertility rates change through time, we can line up our model's age-specific population counts of children and workers fairly closely with those forecast for the three regions.

With respect to the life span uncertainty, we assume that agents die with realistic mortality probabilities starting at age 68. Agents, in our model, fully appreciate the uncertainty of their longevities and maximize, at any point in time, their expected remaining lifetime utilities. The inclusion of lifespan uncertainty provides three advantages in addition to getting agents to die on time. First, it permits a more realistic modelling of bequests and inheritances. The standard method for including bequests in dynamic simulation models is to tack on an extra element to the lifetime utility function that depends on the level of bequests. Our approach here is quite different. We generate bequests by assuming, realistically, that agents fail to annuitize their assets in old age. Hence, when they die, they leave undesired bequests to their children. This treatment of bequests finds support in a recent study by Gokhale, Kotlikoff, Sefton, and Weale (2001), which shows that undesired bequests can explain both the level, Gini coefficient, and skewness of bequests in the U.S.

The second advantage involves the age-distributions of bequests and inheritances. With the exception of De Nardi, İmrohoroğlu, and Sargent (1999), previous modelling of bequests in dynamic models have assumed that all agents die at a given age and all agents inherit at a given age. In our model, agents die at different ages, based on realistic mortality probabilities, and their heirs inherit at different ages. Older heirs who were born when the parents were young receive inheritances later in their life than their younger siblings. The third advantage of incorporating uninsurable lifespan uncertainty is that it leads to a gradual decline in consumption in old age. This is another feature of actual longitudinal age-consumption profiles.

Our model also includes capital adjustment costs. As is well known, these costs can 
drive temporary wedges between the marginal products of capital in different regions and lead the market values of capital assets to temporarily differ from their replacement costs. Thus inclusion of adjustment costs in the model generates what amounts to regional stock markets and permits us to explore how aging and immigration policy affect stock prices through time.

A final feature of our framework worth flagging is the intra-cohort disaggregation. As in Fehr (2000) and Kotlikoff, et. al. (2001), we distinguish three income classes with different earnings abilities within each generation. Immigrants are also split into these income classes so that we can simulate the arrival of immigrants with different stocks of human and physical capital.

We now provide an overview of our model. A more detailed description of the model, including its population projections, data sources, assumptions, and calibration, is provided in Fehr, et. al. (2003).

\section{Demographics}

Each region is populated by households who live up to a maximum age of 90 . Consequently, there are 91 generations with surviving members at any point in time. The individual life cycle of a representative agent is described in Figure 1. Between ages 0 and 20 our agents are children who earn no money and are supported by their parents. At age 21 our agents leave their parents and go to work. Between ages 23 and 45 our agents give birth to fractions of children at the beginning of each period, i.e. the first (fraction of) children are born when the agents are 23 and the last are born when they are age 45. An agent's first-born children (fractions of children) leave home when the parents are age 43, while the last-born leave when the agents are age 66. Our agents die between ages 68 and 90. The probability of death is one at age 91. Children always outlive their parents, meaning that parents always outlive grandparents. To see this note that if a parent reaches age 90 , his or her oldest children will be 67 . These are children who were born when the parent was age 23 .

In each year new immigrants in each skill and age group arrive with the same number and age distribution of children and the same level of assets as natives with the same skill and 
of the same age. Since the demographic structure is identical across countries, it suffices in the following to concentrate on a representative country and omit country indices.

To specify the current and future demographic structure of each region we start with the year-2000 age-specific population $[\bar{N}(a, 2000)]$ and age-specific net-immigration $[\overline{N M}(a, 2000)]$ counts. To determine the evolution over time of population in each region, we applied regionand age-specific mortality $[d(a, i)]$ and birth rates to the cohorts alive in year 2000 as well as to their children as they reach their ages of fertility and mortality.

In constructing existing as well as future age-population counts, we have to link each initial cohort between the ages of 1 and 68 to those of their parents who are still alive. The reason is that children receive bequests from their parents and the levels and timing of these inheritances depend on the ages of their parents. This linkage is achieved by applying past fertility rates to each cohort under age 69 in year 2000. If, for example, 15 percent of the parents of newborns in 1980 were 25 years old, then 15 percent of the 20 -year-olds in year 2000 are assigned to parents age 45. In addition, each cohort is split into three income classes $k$. Specifically, we assume that 30 percent of each cohort belong to the lowest income class, 10 percent to the top income class, and the remaining 60 percent to the middle income class. Formally, we denote the final population vector for year 2000 as $N(a, 2000, s, k)$ where $a=$ $1, \ldots, 90, s=23, \ldots, 45, k=1,2,3$. The term $s$ references the age of the parent at the time of birth of agents age $a$ in 2000 .

We use the population age structure in year 2000 as well as projected future fertility, mortality, and net-immigration rates to compute the population vector $N(a, t, s, k)$ for the years $t$ between 2001 and 2050. After year 2050, mortality and net immigration rates are kept constant and fertility rates are endogenously adjusted in order to achieve a stable population age structure in the future. In the baseline path, we assume annual net-immigration of 1 million per year in the US, 450,000 in the EU, and 54,000 in Japan. Figures 2 and 3 report our projected life expectancy and the fertility rates in the three regions between 2000 and 2100 .

Our exogenous predictions of the current and future mortality and fertility rates follow 
the medium variant of United Nations Population Division (UNPD) (2003). While mortality is decreasing in all three regions until 2050, the Japanese have significantly higher life expectancy than do Americans or EU citizens. Since our model's agents don't die prior to age 68, our agent's life expectancies at birth are higher than the actual values. However, the model's life expectancies conditional on reaching age 60 are close to those reported by the UNDP (2003).

Total fertility rates are currently much higher in the U.S. than in Japan or in Europe. While the Japanese and European rates are predicted to increase until 2050, the U.S. rate is expected to remain at close to its current value. The drop in the U.S. fertility rate starting in 2050 reflects our assumption of zero population growth in all three regions after that year. In the U.S. the high rate of immigration, which we assume continues after 2050, requires a reduction in the fertility rate after 2050 to achieve zero population growth ${ }^{2}$. Figures 4 and 5 report the resulting change in the total population and the dependency ratio.

Due to its relatively high fertility and immigration rates, the U.S. population increases from 275 million in 2000 to 505 million in 2100. In Europe, the total population falls over the century from 375 to 340 million. And in Japan, the population falls from 126 million to only 83 million! As one would expect, dependency ratios are increasing in all three regions up to 2050. However, the three regions experience important differences in their population aging. First, the increase in the dependency ratio is much greater in Japan and Europe than in the US. Second, dependency ratios fall in Europe and Japan after peaking in year 2050, while they remain roughly stable after 2030 in the US.

As agents age, their household compositions change as they have more children and as older children reach adulthood. These changes materially alter consumption and saving decisions. Given age $a$ of an agent in income class $k$ in a specific year $t$, the number of her children

\footnotetext{
${ }^{2}$ Alternatively, one could also keep fertility almost constant and eliminate immigration after 2050. The baseline path after 2050 would not change qualitatively, but national income, capital stock and effective labor supply in the U.S. would increase somewhat less in the long run.
} 
is calculated as

$$
K I D(a, t, k)=\sum_{j=u}^{m} \frac{N(j, t, a-j, k)}{\sum_{s=23}^{45} N(a, t, s, k)} \quad 23 \leq a \leq 65, k=1,2,3,
$$

where $u=\max (0 ; a-45)$ and $m=\min (20, a-23)$. Recall that agents younger than 23 have no children and those over 65 have only adult children, i.e. $K I D(a, t, k)=0$ for $0 \leq a \leq 22$ and $66 \leq a \leq 90$. Agents in between these ages have children. Take, for example, a 30 year-old agent. Such an agent has children who were born in the years $(a-j)$ in the years since she/he was 23. In year $t$, these children are between age $0 \leq j \leq 7$. The kids function (1) sums the total number of kids of the respective parent-income class generation and divides it by the total number of parents of age $a$ in year $t$ who belong to income class $k$. The KID-function (1) takes into account that the family's age structure will change over time due to changing fertility. Our approach also permits the distribution of births by the age of parents to change over time. This is an important improvement compared to Kotlikoff, et. al. (2001).

\section{Preferences and Household Budget Constraints}

As previously mentioned, we do not distinguish between natives and immigrants in the model once the immigrants have joined the native earnings- and age-specific cohorts. The model's preference structure is represented by a time-separable, nested, CES utility function. Remaining lifetime utility $U(j, t, s, k)$ of a generation of age $j$ at time $t$ whose parents were age $s$ at time of birth and who belongs to income class $k$ takes the form

$$
U(j, t, s, k)=V(j, t, s, k)+H(j, t, s, k),
$$

where $V(j, t, s, k)$ records the agent's utility from her/his own goods and leisure consumption and $H(j, t, s, k)$ denotes the agent's utility from the consumption of her/his children. The two sub-utility functions are defined as follows:

$$
\begin{aligned}
& V(j, t, s, k)=\frac{1}{1-\frac{1}{\gamma}} \sum_{a=j}^{90}\left(\frac{1}{1+\theta}\right)^{a-j} P(a, i)\left[c(a, i, s, k)^{1-\frac{1}{\rho}}+\alpha \ell(a, i, s, k)^{1-\frac{1}{\rho}}\right]^{\frac{1-\frac{1}{\gamma}}{1-\frac{1}{\rho}}} \\
& H(j, t, s, k)=\frac{1}{1-\frac{1}{\gamma}} \sum_{a=j}^{90}\left(\frac{1}{1+\theta}\right)^{a-j} P(a, i) K I D(a, i, k) c_{K}(a, i, s, k)^{1-\frac{1}{\gamma}}
\end{aligned}
$$


where $c(a, i, s, k)$ and $\ell(a, i, s, k)$ denote consumption and leisure, respectively and $i$ is defined as $i=t+a-j$. The children's consumption of income class $k$ parents who are age $a$ at period $i$ and whose parents were age $s$ at the time of their birth is defined as $c_{K}(a, i, s, k)$. Note that the number of children is independent of the grandparents' age at the time of the birth of the parents.

Since lifespan is uncertain, the utility of consumption in future periods is weighted with the survival probability of reaching age $a$ in year $i$

$$
P(a, i)=\prod_{u=j}^{a}[1-d(u, u-a+i)]
$$

which is determined by multiplying the conditional survival probabilities from year $t$ (when the agents age is $j$ ) up to year $i$. Note that $\mathrm{d}(\mathrm{j}, \mathrm{t})$ is the mortality probability of an agent age $j$ in year $t$. The parameters $\theta, \rho, \alpha$ and $\gamma$ represent the "pure" rate of time preference, the intratemporal elasticity of substitution between consumption and leisure at each age $a$, the leisure preference parameter, and the intertemporal elasticity of substitution between consumption and leisure in different years, respectively.

Given the asset endowment $\mathrm{a}(j, t, s, k)$ of the agent in year $t$, maximization of $(2)$ is subject to a lifetime budget constraint defined by the sequence:

$$
\begin{aligned}
\mathrm{a}(j+1, t+1, s, k)=[\mathrm{a}(j, t, s, k)+ & I(j, t, s, k)](1+r(t))+w(t) E(a, k)[h(a, t)-\ell(a, t, s, k)] \\
& -T(j, t, s, k)-c(j, t, s, k)-K I D(j, t, k) c_{K}(j, t, s, k),
\end{aligned}
$$

where $r(t)$ is the pre-tax return on savings and $I(j, t, s, k)$ denotes the inheritance the agent receives in year $t$. When the parents die between age 68 and 90, their remaining assets are split between their children. Consequently, inheritances of agents who are age $j$ in year $t$ and whose parents were age $s$ at their birth are defined as follows:

$$
I(j, t, s, k)=\frac{d(j+s) \bar{A}(j+s, t, k)}{\sum_{u=23}^{45} N(j+s-u, t, u, k)} .
$$

The numerator defines the aggregate assets of income class $k$ parents who die in year $t$ at age $j+s$. The denominator defines these parents' total number of children who are between 
ages $j+s-45$ and $j+s-23$ in year $t$. The receipt of inheritances requires us to distinguish members of each cohort according to the ages of their parents at birth. The parents' ages at death determine when the children receive their inheritances. While the first children of parents (born when their parents were age 23) receive their inheritances between ages 45 and 67, the last-born children (born when their parents were age 45) receive their inheritances earlier in life, between ages 23 and 45 .

As in Altig et al. (2001) and Kotlikoff et al. (2001), we assume that technical progress causes the time endowment $h(\cdot)$ of each successive generation to grow at the rate $\lambda$, i.e.

$$
h(a, i)=(1+\lambda) h(a, i-1)
$$

Gross labor income of the agent in year $t$ is derived as the product of her/his labor supply and her/his wage rate. The latter is the product of the gross wage rate $w(t)$ in period $t$ and the age- and class-specific earnings ability.

$$
\begin{aligned}
E(a, k)=\xi(k) e^{4.47+0.033(a-20)-0.00067(a-20)^{2}}(1+\lambda)^{a-21} & \text { with } \\
& \xi(1)=0.2, \xi(2)=1.0, \xi(3)=5.0
\end{aligned}
$$

The middle-income class profile is taken from Auerbach and Kotlikoff (1987, 52). The shift parameters $\xi(k)$ are then applied to derive income class-specific profiles. Moreover, since technological change is an important determinant of secular growth over the life cycle, we add this growth by multiplying the age-specific longitudinal earnings ability profile by the term involving $\lambda$. Hence, the longitudinal age-wage profile is steeper the greater is the rate of technological change.

The net taxes $T(j, t, s, k)$ of an agent in year $t$ consist of consumption, capital income, and progressive wage taxes as well as social security contributions net of pensions. Due to a contribution ceiling, pension, disability insurance and health-care contribution rates may differ across agents. Each agent's pension benefits depend on her/his pre-retirement earnings history, while health care and disability transfers are provided on a per capita basis to all eligible age groups. 
Given individual consumption, leisure, and asset levels of all agents, we can compute the aggregate variables. For example, aggregate value of assets $A(t+1)$ in period $t$ is computed from

$$
A(t+1)=\sum_{k=1}^{3} \sum_{a=21}^{90} \underbrace{\sum_{s=23}^{45} \mathrm{a}(a+1, t+1, s, k) N(a, t, s, k)}_{\bar{A}(a+1, t+1, k)}
$$

Since households die at the beginning of each period, we have to aggregate across all agents who lived in the previous period in order to compute $\bar{A}(a+1, t+1, k)$, which we need for the calculation of bequests, see (7). If we aggregate across agents who live in period $t+1$, i.e.,

$$
\mathcal{A}(t+1)=\sum_{k=1}^{3} \sum_{a=21}^{90} \sum_{s=23}^{45} \mathrm{a}(a, t+1, s, k) N(a, t+1, s, k)
$$

assets of the arriving immigrants of period $t+1$ are included.

Finally, aggregate labor supply of agents in year $t, L(t)$, is computed from the individual labor supplies, i.e.

$$
L(t)=\sum_{k=1}^{3} \sum_{a=21}^{90} \sum_{s=23}^{45} E(a, k)[h(a, t)-\ell(a, t, s, k)] N(a, t, s, k) .
$$

\section{The Government Sector}

The consolidated government issues new debt $\Delta B(t)$ and collects net-taxes in order to finance general government expenditures $G(t)$ as well as interest payments on its debt.

$$
\Delta B(t)+\sum_{k=1}^{3} \sum_{a=21}^{90} \sum_{s=23}^{45} T(a, t, s, k) N(a, t, s, k)=G(t)+r(t) B(t) .
$$

With respect to public debt, we assume that the government maintains an exogenously fixed ratio of debt to output. The progressivity of the wage tax system is modelled as in Auerbach and Kotlikoff (1987). Specifically, marginal wage tax rates rise linearly with the tax base.

$P Y(t)$ defines the aggregate payroll tax base, which differs from total labor earnings due to the ceiling on taxable wages. This ceiling is fixed at twice average income in the U.S. and EU and at 168 percent of average income in Japan. Aggregate average social security payroll 
tax rates $\hat{\tau}^{p}, \hat{\tau}^{h}$ and $\hat{\tau}^{d}$ are computed each period from the relevant budget constraint for the program and region in question. For the U.S., we determine the separate values of payroll tax rates for the Social Security pension system, Medicare, and the Social Security disability insurance systems, i.e.

$$
\hat{\tau}^{p}(t) P Y(t)=P B(t) \quad \hat{\tau}^{h}(t) P Y(t)=H B(t) \quad \text { and } \quad \hat{\tau}^{d}(t) P Y(t)=D B(t)
$$

where $P B(t), H B(t)$ and $D B(t)$ are total outlays of the pension, health care, and disability systems, respectively. In the EU and Japan, disability insurance is part of their respective state pension systems. Hence, we do not calculate separate disability insurance payroll tax rates for those regions.

Due to contribution ceilings, individual pension and health insurance payroll tax rates can differ from the payroll tax rate. Above the contribution ceiling, marginal social security contributions are zero and average social security contributions fall with the agent's income. To accommodate this non-convexity of the budget constraint, we assume that the highest earnings class in each region pays pension and in the EU and Japan, health insurance payroll taxes, up to the relevant ceilings, but faces no pension and no health care payroll taxes at the margin. The other earnings classes are assumed to face the full statutory rate on all earnings. In the U.S., the disability payroll tax is modelled in an equivalent manner. However, since there is no ceiling on U.S. Medicare taxes, all earnings groups are assumed to face the health insurance payroll tax at the margin.

If a $k$-income class agent, whose parents were $s$ years old at his birth, retires in year $z$ at the exogenously set retirement age $\bar{a}(z)$, her/his pension benefits $\operatorname{Pen}(a, i, s, k)$ in years $i \geq z$ when he is age $a \geq \bar{a}(z)$ depend linearly on her/his average earnings during his working time $\bar{W}(z, s, k)$ :

$$
\operatorname{Pen}(a, i, s, k)=\omega_{0}+\omega_{1} \times \bar{W}(z, s, k) .
$$

The region-specific parameters $\omega_{0}, \omega_{1}$ were chosen in order to approximate the replacement rates relative to individual lifetime earnings as reported in Whitehouse (2002).

General government expenditures $G(t)$ consist of government purchases of goods and ser- 
vices, including educational expenditures and health outlays. Over the transition, government purchases of goods and services are held fixed per capita with an adjustment for annual technological change. Age-specific education, health, and disability outlays are also held fixed over the transition with the same adjustment for technological change. The government's budget (13) is balanced each year by adjusting the intercept on our linear formula for the average wage tax rate.

\section{Production}

The economy is populated by a large number of identical firms, the total number of which we normalize to unity. Aggregate output (net of depreciation) is produced using Cobb-Douglas production technology, i.e.

$$
F(K(t), L(t))=\phi K(t)^{\varepsilon} L(t)^{1-\varepsilon}
$$

where $K(t)$ is aggregate capital in period $t, \varepsilon$ is capital's share in production, and $\phi$ is a technology parameter. Since we posit convex capital adjustment cost, the firms' marketable output in year $t, Y(t)$, is given by the difference between gross output and adjustment costs, i.e.

$$
Y(t)=F(K(t), L(t))-0.5 \psi \Delta K(t)^{2} / K(t)
$$

where $\Delta K(t)$ measures investment in year $t$. The term $\psi$ is the adjustment cost coefficient. Larger values of $\psi$ imply higher marginal costs of new capital goods for a given rate of investment. The installation technology is linear homogeneous and shows increasing marginal cost of investment (or, symmetrically, disinvestment): faster adjustment requires a greater than proportional rise in adjustment costs.

We abstract from any taxation at the corporate level. Arbitrage between new and existing capital, therefore, implies that the latter has a price per unit of

$$
q(t+1)=1+\psi \Delta K(t) / K(t)
$$

Similarly, the arbitrage condition arising from profit maximization requires identical re- 
turns to financial and real investments.

$$
r(t) q(t)=F_{K(t)}+0.5 \psi(\Delta K(t) / K(t))^{2}+q(t+1)-q(t)
$$

The left side gives the return on a financial investment of amount $q(t)$, while the return on one unit of real capital investment is the net return to capital (which includes the marginal product of capital $F_{K(t)}$ plus the reduction in marginal adjustment costs) and capital gains.

\section{World Equilibrium}

Up to now we've described the model for the representative economy. In the open economy case, the aggregate value of world assets equals the market value of the world-wide capital stock plus the value of all outstanding regional government bonds:

$$
\sum_{x \in W} \mathcal{A}(t, x)=\sum_{x \in W}[q(t, x) K(t, x)+B(t, x)], \quad \text { with } \quad W=\{U . S ., E U, \text { Japan }\} .
$$

\section{Solving the Model}

To solve the model we first need to specify the preference, technology, and policy parameters. Table 1 reports our main parameter values. The preference and technology parameters are mostly taken from Kotlikoff, et. al. (2001). The reported debt levels in USA, Europe and Japan were chosen to match real interest payments reported in European Commission (2003) for the year 2000, while the retirement ages are taken from Bloendal and Scarpetta (1999) for the US and the EU and from Whitehouse (2002) for Japan. The consumption tax rate for the US is taken from Kotlikoff, et. al. (2001). For the EU, the consumption tax rate is the unweighted average of the indirect tax rates in the member states. In the case of Japan, the consumption tax rate is set at the current value of the VAT. In addition, we specify the progressive parameters of the wage tax systems in each region in order to generate realistic average and marginal tax rates (reported below), while the proportional term is computed endogenously so that the government budget is balanced by the wage tax.

In calibrating our model, we use a Japanese age-specific government health care expen-

ditures profiles for Japan. In the case of the EU, we use the German profile. For the U.S., 
the Medicare program applies only to households older than 65. We assume uniform Medicare expenditures by age among those over age 65. We make the same uniform age-distribution assumption with respect to the U.S. disability system, which we assume applies to only those under age 65 .

We use the German age-specific education profile for all regions in the model and rescale it to get realistic education outlays in year 2000 in each region (see below). In addition to these parameter values, our model requires an initial distribution of assets by age and income class for each region. These profiles are region-specific. ${ }^{3}$

To run our model as an open world economy, we also need to specify how aggregate world assets are distributed across regions. These world asset shares were chosen to generate realistic current accounts vis a vis the other regions for our initial year. Finally, we have to specify the capital stocks in each region in our initial year 2000 in each region. Here we take the endogenous initial-year values that arise from a simulation without adjustment costs.

Given the initial world capital stock and asset profiles, our model applies a Gauss-Seidel algorithm to solve for the perfect foresight general equilibrium transition path of the economy. Our algorithm starts with initial guesses for the capital stocks and labor supplies in each region for the remaining years of the transition. Next we compute from equation (18) the path of region-specific market prices of capital. The path for the world interest rate after 2000 is derived from the arbitrage condition (19) for the U.S. This condition (19) is also used to update values of the existing capital stock in year 2000 in each region. Next, the wage rates are computed in each region by setting them equal to their respective marginal products of labor. From the capital market equilibrium condition (20) we derive aggregate initial asset holdings in year 2000, apply the region-specific saving shares, and update age-specific asset holdings in 2000 in each region. Given these initial assets, the time path of tax rates (which are based on guesses in the first iteration) and factor prices, household decisions on consumption and

\footnotetext{
${ }^{3}$ Data on Japanese asset profiles were provided by Charles Horioka, while the European profiles were adjusted from German data provided by Reinhold Schnabel. U.S. Data were derived from the 1998 Survey of Consumer Finances.
} 
labor supply are computed and aggregated. Then we update the path for wage tax rates, the social security payroll tax rate, and debt given the government budget constraints (13) and (14). Finally, we compute new paths for the capital stocks in each region using the capital market equilibrium condition (20) as well as (18). The new values for capital and labor are then weighted with the initial guesses of these supplies to form guesses of the time paths of these variables. The algorithm then iterates until the path of capital stock and labor converges. We give our economy 300 years to reach to a steady state. Our model in fact reaches a steady state to many decimal places prior to year 300. It also converges very tightly around the equilibrium transition path.

\section{Initial Equilibrium and the World Economy's Baseline Transition Path}

Table 2 reports the macroeconomic variables in 2000 in the three regions. Note that there is a fairly close accordance between actual and computed national income account measures of private consumption and government purchases. The one exception here is Japanese government purchases. The official data seem too high given the reported ratio of tax revenues to national income. In our calibration, we chose to benchmark government purchases based on the ratio of tax revenues to national income.

The reported shares in education, pensions and health are very close to actual levels ${ }^{4}$. The same applies to the social security payroll tax rates and the level and progressivity of the income tax in the U.S. and EU. On the other hand, the average wage tax rate in Japan is high. Since we have assumed a fairly low consumption tax rate in Japan (see table 1), tax revenues from indirect taxes are too low in Japan ${ }^{5}$. Finally, the model's year-2000 capital-output ratios seem reasonable not only with reference to U.S. Commerce Department figures, but also in terms of the year-2000 interest rate, which equals 9.0 percent. Having said this, we point out below that calibrating the model to a lower initial capital-output ratio will alter the extent to which simulated capital-labor ratios decline and real wages fall over the develop world's transition path.

\footnotetext{
${ }^{4}$ See European Commission (2003), Dang et al. (2001, 26), IPSS (2003, 3) and OECD (2002, 178 and 2003).

${ }^{5}$ In future research we plan to improve this calibration.
} 
We now turn to our simulated baseline policy transition paths for the three regions, which are reported in the upper panels of tables 3 to 5 for the U.S., EU and Japan. The findings here are not pleasant. First, rather than enjoying the economic fruits of capital deepening, the developed world experiences a major capital shortage - one that lowers real wages per unit of human capital by almost one fifth between now and the end of this century! The corresponding century-long increase in real interest rates is 440 basis points.

The explanation for this predicted capital shortage lies in the last two columns of the charts. There we see combined social insurance payroll tax and wage tax rates rising by 73 percent in the U.S., 66 percent in the EU, and by 64 percent in Japan. These tax hikes dramatically reduce the ability of workers in the developed world to save over the course of this century. By 2100, the combined payroll plus average wage tax rate equals 40.7 percent in the U.S., 67.7 percent in the EU, and 63.3 percent in Japan.

One way to gauge the importance of fiscal policy to this finding is to turn off the social security, disability, and health care programs and rerun the baseline simulation. Doing so reduces the severity of the capital shortage by roughly half; i.e., the decline in real wages over the transition is roughly half of what arises when these social insurance programs are in place.

We also reran this baseline simulation assuming an initial capital-output ratio of 2.5 in each region. The year-2000 interest rate in this case is 10.0 percent and the real wage declines over the century by only 6 percent over the century rather than the 19 percent decline reported in tables 3 to 5 . In the absence of social insurance programs, this alternatively calibrated model generates a long-run crowding in of capital that raises the 2100 real wage by 5.0 percent $^{6}$. So the key message here is that regardless of the initial capital-labor ratio to which one calibrates, the presence of social insurance programs can substantially limit the amount of crowding in of capital that would otherwise arise due to the aging of developed economies.

Although each of the regions experience the same reduction in real wages and dramatic tax increases, there are significant differences with respect to overall economic growth. In the U.S.,

\footnotetext{
${ }^{6}$ We're currently double checking these results in the closed and open economies.
} 
national income grows by a factor of 4.1 over the century. In the EU, it grows by a factor of 2.2. And in Japan, it grows by a factor of only 1.4. The explanation here is major differences across the regions in the growth of effective labor supply. Although each region experiences the same technological change, which permits greater effective labor supply by each successive cohort, the absolute number of workers grow at much different rates in the three regions. Indeed, in Japan and the EU the reduction in population size means a reduction over time in the absolute numbers of workers in those regions. The base case run also suggests a major rise in stock values over the course of the century. This is to be expected given the capital scarcity arising along the transition path. Note that the long run value of $q$ is 1.1 in all regions of the model.

\section{Immigration Policy}

In this section we consider the macroeconomic and welfare effects of five alternative immigration policies: doubling immigration in all three regions, doubling immigration in just the U.S., doubling low-skilled immigration in just the U.S., doubling high-skilled immigration just in the U.S., and doubling the number of elderly immigrants in the U.S.

\section{Doubling of Immigration in All Three Regions}

The second panels in tables 3 through 5 show the impacts of immediately and permanently doubling immigration in all three regions. As is clear from the figures for effective labor supply, doubling immigration makes a material difference to the long-run supply of labor in all three regions. Relative to the baseline simulation, this policy raises effective labor supply in 2100 by 31 percent in the U.S., by 21 percent in the EU, and by 11 percent in Japan. The remarkable thing is how long it takes for immigration to materially alter effective labor supplies. In the U.S., for example, the effective supply of labor is only 13 percent larger in 2030 despite a doubling of immigration starting in 2000. The comparable figures for the EU and Japan are 6 percent and 2 percent.

Given that the developed world's severe fiscal problems associated with aging will begin to appear well before 2030, it would seem that even a doubling of immigration is "too little

too late"'. This, indeed, is what the other figures in the second panel of results show. Relative 
to the baseline simulation, doubling immigration makes little difference to any of the three countries in terms of their macroeconomic variables.

Take the U.S. In 2030 the social insurance payroll tax rate is 21.5 percent with a doubling of immigration, which is not much lower than the 23.1 percent rate without the extra immigrants. In 2100 the payroll tax rate is 26.7 percent, compared with 27.4 percent under base-case immigration policy. Factor prices are also essentially unchanged by a doubling of immigration. In 2030, the pre-tax wage is .88 compared with .90 in the base case. And in 2100, the pre-tax wage is .81 in both simulations. The explanation here is that while the long-run U.S. labor supply rises by 31 percent, the long-run capital stock rises by 33 percent, leaving the long-run capital-labor ratio essentially unchanged.

If the long-run real wage in the U.S. stays fixed, but labor supply rises by 31 percent, why doesn't the payroll tax rate and, for that matter, the average wage tax rate fall by 31 percent in light of the 31 percent larger long-run supply of effective labor? The answer is that the model provides new immigrants with public goods and social insurance benefits on the same basis as existing natives. And doubling the number of immigrants on an across-the-board basis ends up costing the U.S. government almost as much in additional expenditures as the U.S. government earns in additional revenues. As tables 4 and 5 indicate, the same can be said of the EU and Japan.

Table 6 reports the welfare effects from doubling immigration. The numbers show the change in welfare measured as an equivalent variation and expressed as a percentage of remaining lifetime resources for cohorts born between 1910 and 2030. Almost all cohorts realize welfare gains, albeit mostly very small ones, from the doubling of immigration. The elderly mainly benefit from the increased capital prices. Initially younger and future generations gain from the reduction in payroll taxes. The gains are smaller for members of the high-skilled class because the ceiling on key payroll taxes limits the benefits they can experience from cuts in these taxes.

Welfare gains are generally higher in the EU and Japan. This is particularly true of 
younger and future cohorts. Indeed, for the EU low-skilled cohort born in 2030, the welfare gain is 5.85 percent in the EU, 3.40 percent in Japan, and only 1.58 percent in the U.S. Unlike the gains of initial older generations, these gains are substantial. They appear to reflect the reduction in excess burden arising from even the modest reductions in marginal tax rates arising from the immigration reform. As is well known, the size of the efficiency gain from reducing effective marginal tax rates depends on their initial level. And in the EU and Japan, base-case effective marginal tax rates are much higher than they are in the U.S.

\section{Doubling Immigration in the U.S.}

In the third panel of tables 3-5, we consider doubling immigration, but only in the U.S. The goals here number two. First, we want to assess possible spillovers across regions from unilateral immigration policy. Second, we want to examine what may be the most likely immigration policy response to the demographic transition, namely a major expansion of U.S. immigration, with little or no change in EU or Japanese immigration. The reason we view this to be most likely is that the U.S. appears much more open to immigration than the other regions.

As a comparison of panels 2 and 3 in table 3 indicates, doubling immigration just in the U.S. makes almost no difference to the U.S. transition compared with doubling immigration in all three regions. There is also little impact on the EU or Japan of this policy as can be confirmed by comparing panels 1 and 3 for those two counties in tables 4 and 5 . This makes sense. As we've seen, doubling immigration has even in the long run only little effect on the world-wide capital-labor ratio. Hence, conducting this policy in the U.S. makes little difference to the one channel by which it could affect the EU and Japan, namely the developed world's degree of capital intensivity. The fact that both asset accumulation and labor supply rise in roughly the same proportion in the U.S. also explains why this policy only increases the flows of capital from the US to the EU and Japan slightly as measured by the later two region's current accounts. The final piece of evidence confirming the small size of international spillovers from unilateral changes in immigration is given in table 7. There we see welfare changes for the U.S. that are very close to those in table 6, whereas those for the EU and Japan are small, especially 
in the short and medium run. The significant long run welfare effects, for the EU and Japan deserve some comments. They are mainly due to the adjustment of the contribution ceiling for social security contributions. The higher capital inflows increase labor supply, average income and the contribution ceiling in the EU and Japan. Consequently, top income households pay more contributions into the system, although the contribution rate falls. This explains the long run redistribution from rich to poor and medium income households. 


\section{Doubling Low-Skilled Immigration in the U.S.}

Next we assume, as in the previous reform, that U.S. immigration is increased from 1 to 2 million people, but that the increase occurs only with respect to low-skilled immigrants. The fourth panel in tables 3-5 shows the effect of this policy, particularly the fact that compared with the baseline simulation, it raises payroll and wage tax rates substantially and lowers real wages. This reflects the nature of the U.S. state pension system, which provides benefits on a progressive basis and imposes a ceiling on earnings subject to payroll taxation. These features make low-skilled immigrants so expensive that they fail to pay for themselves either with respect to revenue generation or with respect to the accumulation of capital. As the fourth panel shows, the long-run payroll tax rate is 2.1 percentage points higher and the average wage tax rate is 7.1 percentage points higher than in the base case. In addition, real wages end up 2 percentage points lower. This translates into more than an 11 percent decline in long-run after-tax real pay compared with the baseline.

As table 8 shows, this immigration policy is not only bad when measured by changes in macroeconomic variables. It's also quite bad when measured in terms of welfare changes. Indeed, for the low-skilled U.S. cohort born in 2030, the welfare loss is 7.03 percent. For the middle-skilled cohort born in that year, the loss is 6.68 percent. And for that birth year's high-skilled cohort, the loss is 2.67 percent.

Increasing low-skilled immigration turns out not only to be a bad idea for the U.S., but it's also a bad ideal for the EU and Japan. The long-run decline in capital intensitivity and real wages visits non-trivial welfare losses on the lowest and middle-skilled cohorts born in 2030 in the EU and Japan.

\section{Doubling High-Skilled Immigration in the U.S.}

Our next experiment entails doubling from 100,000 to 200,000 the number of high-skilled immigrants assumed to enter the U.S. each year. This is obviously a very major increase in the number of skilled immigrants, but represents only a 10 percent overall rise in U.S. immigration. This, however, counts only bodies. By assumption, high-skilled agents are four 
times as productive as low-skilled workers. So doubling the number of high-skilled immigrants constitutes a larger increase in total effective labor supply.

Compared with our previous immigration policies, this policy comes out on top in terms of its mitigation of future tax hikes. It also leaves long-run real wages somewhat higher than would otherwise be the case. Compared with the base case, the long-run U.S. payroll tax rate is now 26.4 percent instead of 27.4 percent. More importantly, the long-run average wage tax rate is 10.8 percent rather than 13.3 percent. And, as shown in Table 9, future Americans of all skill levels and, indeed, future low- and middle-skilled Europeans and Japanese benefit from this policy. In the case of low-skilled Americans born in 2030, the welfare gain is 3.53 percent. For their European and Japanese contemporaries the welfare gains are .77 percent and .78 percent, respectively.

\section{Doubling Immigration by Elderly in the US}

Our final immigration reform is inspired by Lundborg and Segerstrom (2002) who consider a policy that restricts immigration to workers with significant asset holdings. Since in our model elderly immigrants arrive in their destination country with significant assets, increasing the number of elderly immigrants is a way to explore the effect of letting immigrants "buy their way in." In our experiment we double the 10 percent oldest immigrants to the U.S.

This policy turns out to have very little effect on any of the three economies or on the

welfare of their current or future citizens. The intuition is that there are simply too few elderly immigrants, even when their number is doubled, to materially alter the overall world wide capital-labor ratio.

\section{Conclusion}

This paper asks whether immigration can alleviate the fiscal burden and capital shortage facing the developed world as it embarks on its dramatic demographic transition. Our findings are discouraging. Immigration per se, no matter how large, will do essentially nothing to help the developed world because every dollar, euro, or yen collected from new immigrants in taxes 
will be needed to provide them with public goods and social insurance benefits. Moreover, if the expansion of immigration is concentrated among the low skilled, the developed world's fiscal finances will deteriorate significantly. The only policy that could help the developed world face its demographic dilemma is expanding high skilled immigration. But massive increases in high skilled immigration would be required for such a policy to have a meaningful impact. Where would such immigrants come from? The answer is the underdeveloped world. But whether the developing world has a sufficient number of such workers willing to immigrate remains an open question as does the developing world's willingness to exacerbate what is to them already a very costly brain drain.

\section{References}

Altig, D., A.J. Auerbach, L.J. Kotlikoff, K.A. Smetters and J. Walliser (2001): Simulating Fundamental Tax Reform in the United States, American Economic Review 91, 574-595.

Auerbach, A.J. and P. Oreopoulos (1999): Analyzing the Fiscal Impact of U.S. Immigration, American Economic Review 89, 176-180.

Auerbach, A.J. and L.J. Kotlikoff (1987): Dynamic Fiscal Policy, Cambridge.

Bloendal, S. and S. Scarpetta (1999): The Retirement Decision in OECD Countries, OECD Economics Department Working Paper 202, Paris.

Boersch-Supan, A., A. Ludwig and J. Winter (2002): Ageing and International Capital Flows, in: Auerbach, A.J. and H. Herrmann (eds.), Ageing, Financial Markets and Monetary Policy, pp. 55-83.

Bonin, H., B. Raffelhüschen and J. Walliser (2000): Can Immigration Alleviate the Demographic Burden? FinanzArchiv 57, 1-21.

Brooks, R. (2003): Population Aging and Global Capital Flows in a Parallel Universe, IMF Staff Papers 50, 200-221. 
Dang, T.T., P. Antolin and H. Oxley (2001); Fiscal Implications of Ageing: Projections of Age-related Spending, Economics Department Working Paper No. 305, OECD, Paris.

De Nardi, M., S. İmrohoroğlu and T.J. Sargent (1999): Projected US Demographics and Social Security, Review of Economic Dynamics 2, 575-615.

European Commission (2003): Statistical Annex to European Economy No. 4, Brussels.

Fehr, H. (2000): Pension Reform during the Demographic Transition, Scandinavian Journal of Economics 102, 419-443.

Fehr, H., G. Halder, S. Jokisch and L.J. Kotlikoff (2003): A Simulation Model for the Demographic Transition in the OECD, Discussion Paper, University of Wuerzburg.

Fehr, H., S. Jokisch and L.J. Kotlikoff (2004): The Developed World's Demographic Transition - The Roles of Capital Flows, Immigration, and Policy, forthcoming in: R. Brooks and A. Razin (ed.): The Politics and Finance of Social Security Reform, Cambridge University Press.

Gokhale, J. L.J. Kotlikoff, J. Senfton and M. Weale (2001): Simulating the Transmission of Wealth Inequality via Bequests, Journal of Public Economics 79, 93-128.

INGENUE (2002): Macroeconomic Consequences of Pension Reforms in Europe: An Investigation with the INGENUE World Model, Discussion Paper, Paris.

Institute of Population and Social Security Research (IPSS) (2003): The Cost of Social Security in Japan, Statistical Report No. 13, Tokyo.

Kotlikoff, L.J., K.A. Smetters, J. Walliser (2001): Finding a Way out of America's Demographic Dilemma, NBER Working Paper No. 8258, Cambridge.

Lundborg, P. and P.S. Segerstrom (2002): The Growth and Welfare Effects of International Mass Migration, Journal of International Economics 56, 177-204.

OECD (2002): Education at a glance, Paris. 
OECD (2003): Health Data, 4th ed., Paris.

Storesletten, K. (2000): Sustaining Fiscal Policy through Immigration, Journal of Political Economy 108, 300-323.

United Nations Population Division (2003): World Population Prospects: The 2002 Revision, New York.

Whitehouse, E. (2002): Pension Systems in 15 Countries compared: The Value of Entitlements, Discussion Paper 02/04, Centre for Pensions and Superannuation, Sydney. 
Figure 1: The individual life-cycle

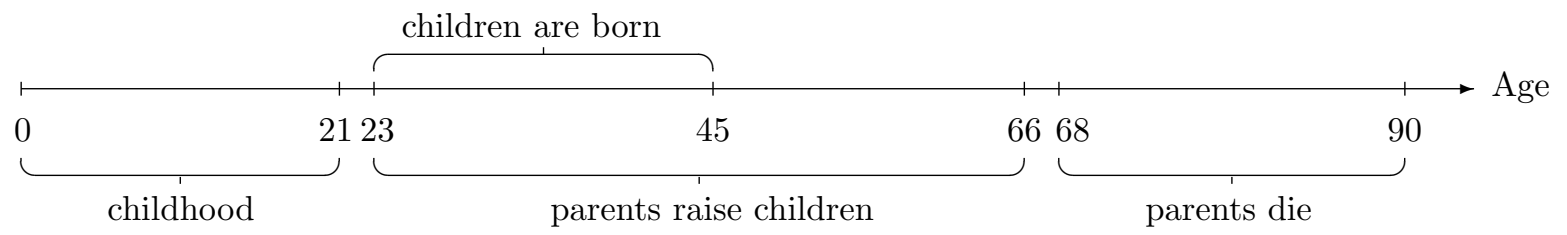

Figure 2: Life expectancy

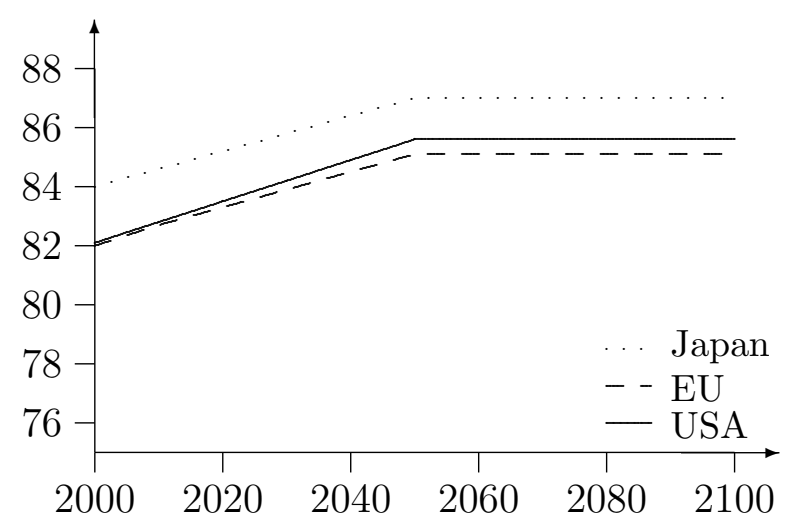

Figure 3: Total fertility (birth per woman)

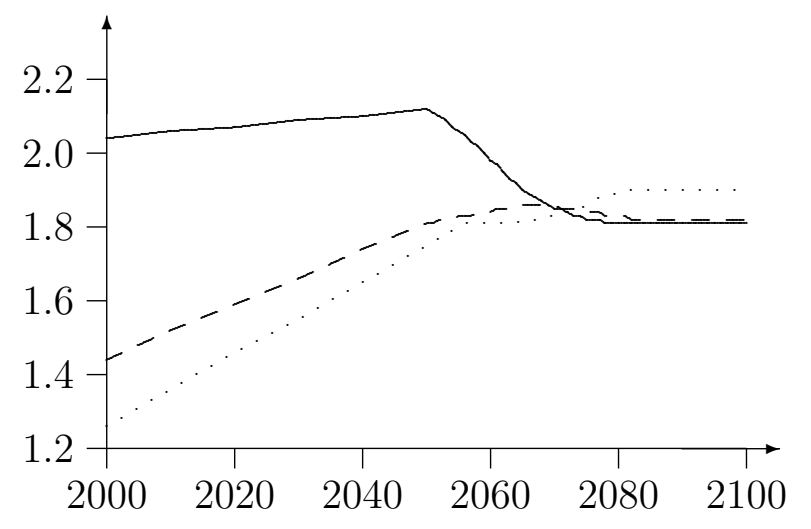


Figure 4: Total population (in mio.)

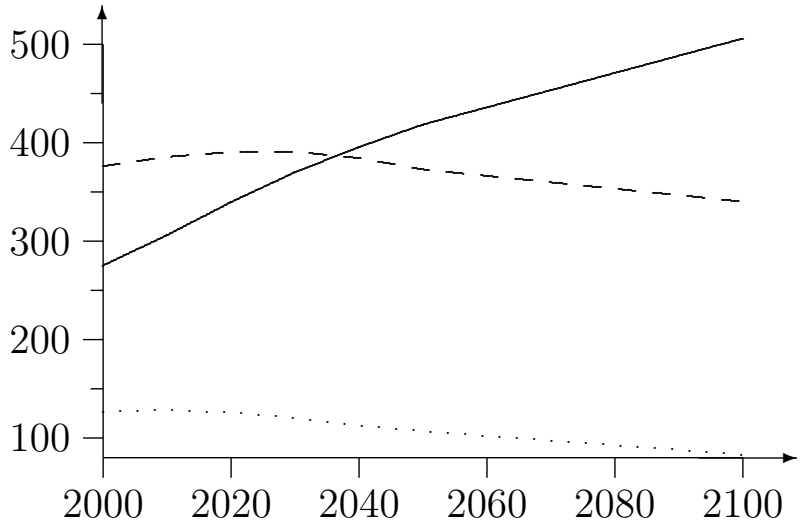

Figure 5: Dependency ratio (60-90/20-59)

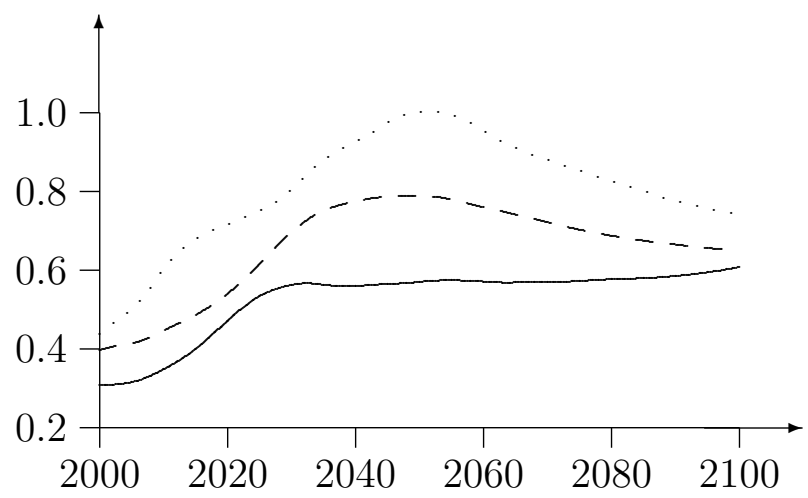

Table 1: Parameter values of the Model

\begin{tabular}{lllll}
\hline & Symbol & \multicolumn{2}{c}{ Value } \\
& & USA & EU Japan \\
\hline Utility function & & & & \\
time preference rate & $\theta$ & 0.02 & \\
intertemporal elasticity of substitution & $\gamma$ & & 0.25 & \\
intratemporal elasticity of substitution & $\rho$ & & 0.4 & \\
leisure preference parameter & $\alpha$ & & & \\
Production function & & & & \\
technology level & $\phi$ & & 0.05461 & \\
capital share in production & $\varepsilon$ & & 0.25 & \\
adjustment cost parameter & $\psi$ & & & \\
technical progress & $\lambda$ & & & \\
Policy parameters & & & 20.0 & \\
consumption tax rate (in \%) & $\tau^{c}$ & 11.3 & 19.5 & 5.0 \\
capital tax rate (in \%) & $\tau^{r}$ & & 20.0 & \\
debt (in \% of NI) & $B / Y$ & 40 & 50 & 44 \\
age of retirement & & 63 & 60 & 60 \\
\hline
\end{tabular}


Table 2: The year 2000 of the baseline path*

\begin{tabular}{|c|c|c|c|c|c|c|}
\hline & \multicolumn{3}{|c|}{ Model } & \multicolumn{3}{|c|}{ Official** } \\
\hline & USA & $\mathrm{EU}$ & Japan & USA & EU & Japan \\
\hline \multicolumn{7}{|l|}{ National Income } \\
\hline private consumption & 77.4 & 69.4 & 78.7 & 77.6 & 67.8 & 67.8 \\
\hline government purchases of goods and services & 22.8 & 32.9 & 22.4 & 23.0 & 32.1 & 33.4 \\
\hline net investment & -0.5 & -1.6 & -2.8 & & & \\
\hline current account & 0.2 & -1.2 & 3.1 & -4.6 & -0.4 & 3.0 \\
\hline national saving rate & 3.1 & 4.1 & 4.1 & 2.8 & 6.3 & 5.6 \\
\hline \multicolumn{7}{|l|}{ Government indicators } \\
\hline aggregate education outlays & 5.9 & 6.0 & 4.4 & 5.9 & 6.0 & 4.3 \\
\hline aggregate pension benefits & 5.9 & 11.4 & 10.8 & 5.7 & 11.6 & 10.8 \\
\hline aggregate health benefits & 2.1 & 6.4 & 5.2 & 2.5 & 6.2 & 6.8 \\
\hline aggregate disability benefits & 1.3 & - & - & 0.9 & - & - \\
\hline pension contribution rate (in \%) & 8.8 & 16.9 & 16.5 & 10.6 & - & 17.3 \\
\hline health care contribution rate (in \%) & 2.8 & 9.6 & 8.0 & 2.9 & - & 8.0 \\
\hline disability insurance contribution rate (in \%) & 1.9 & - & - & 1.9 & - & - \\
\hline interest payment on public debt & 3.6 & 4.5 & 4.0 & 4.2 & 4.5 & 4.0 \\
\hline Tax revenues & 22.3 & 30.3 & 20.9 & 26.6 & 32.5 & 20.7 \\
\hline direct taxes & 13.6 & 16.8 & 17.0 & 17.9 & 16.5 & 10.5 \\
\hline indirect taxes & 8.7 & 13.5 & 3.9 & 8.7 & 16.0 & 10.2 \\
\hline \multicolumn{7}{|l|}{ Wage tax rates (in \%) } \\
\hline average & 10.0 & 14.2 & 14.1 & & & \\
\hline marginal & 17.0 & 19.7 & 20.2 & & & \\
\hline capital output ratio & 3.2 & 3.2 & 3.3 & & & \\
\hline interest rate (in \%) & & 9.0 & & & - & \\
\hline
\end{tabular}

* in per cent of NI if not stated different $\quad * *$ European Commission (2003) 


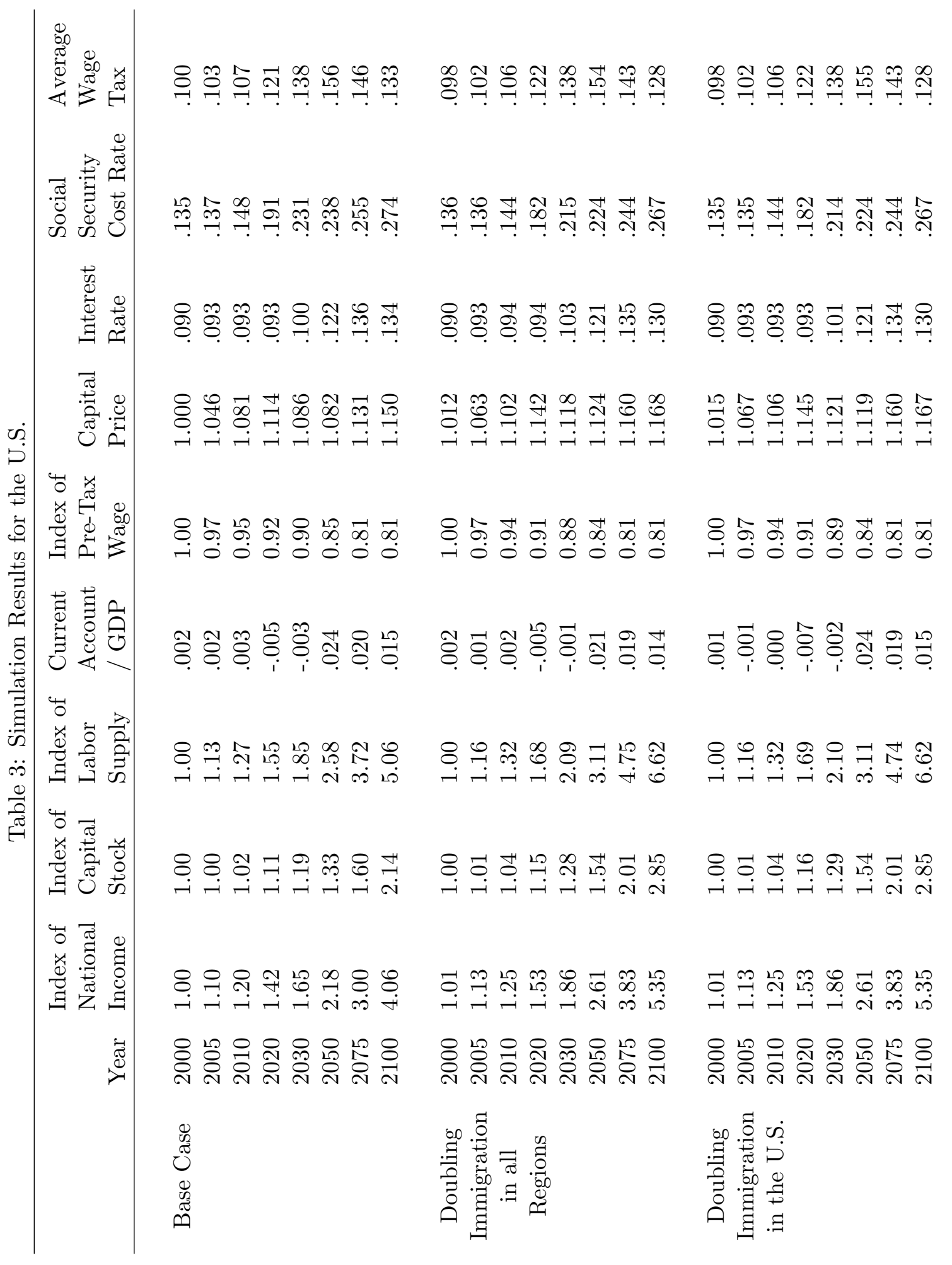




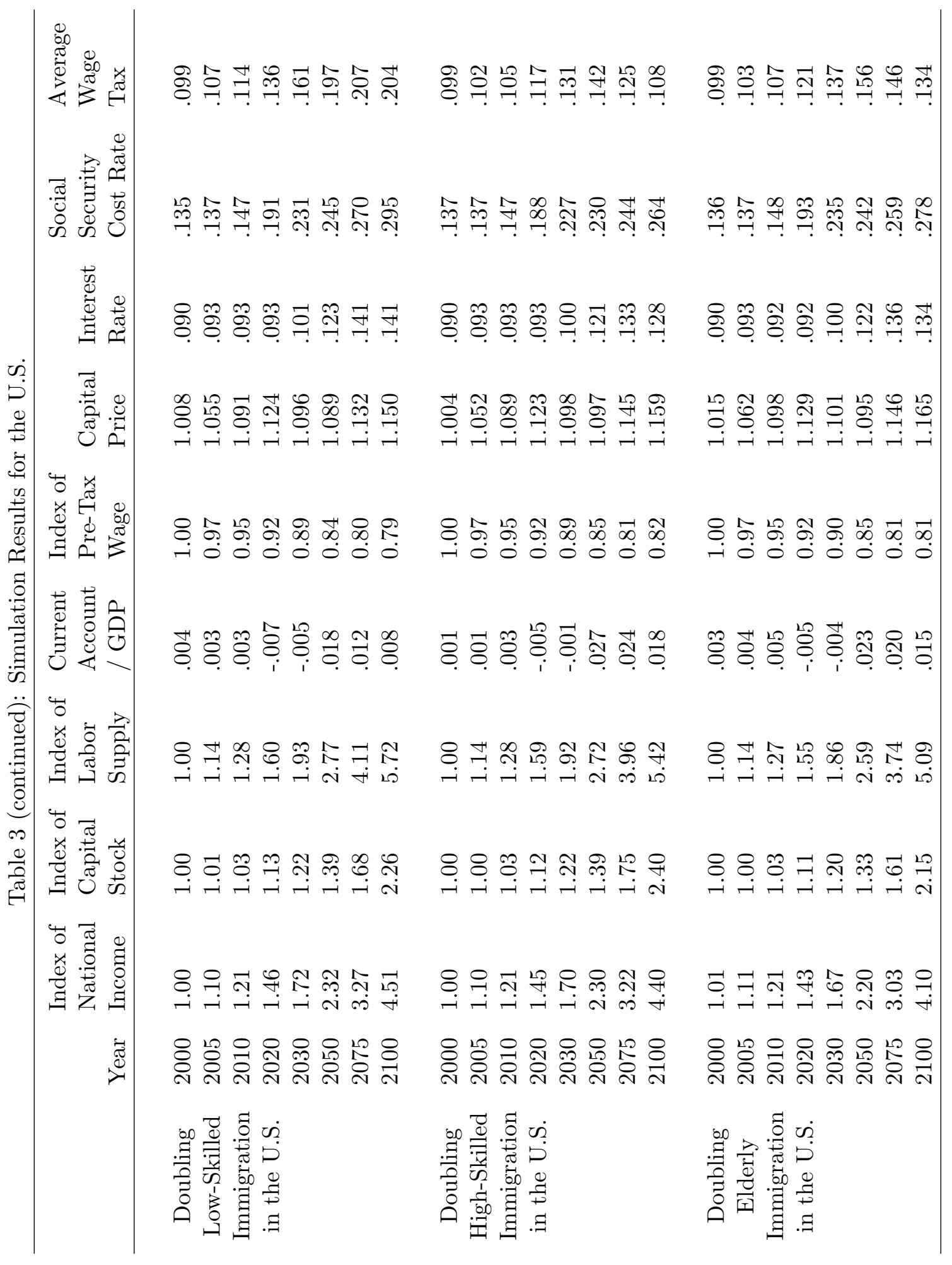




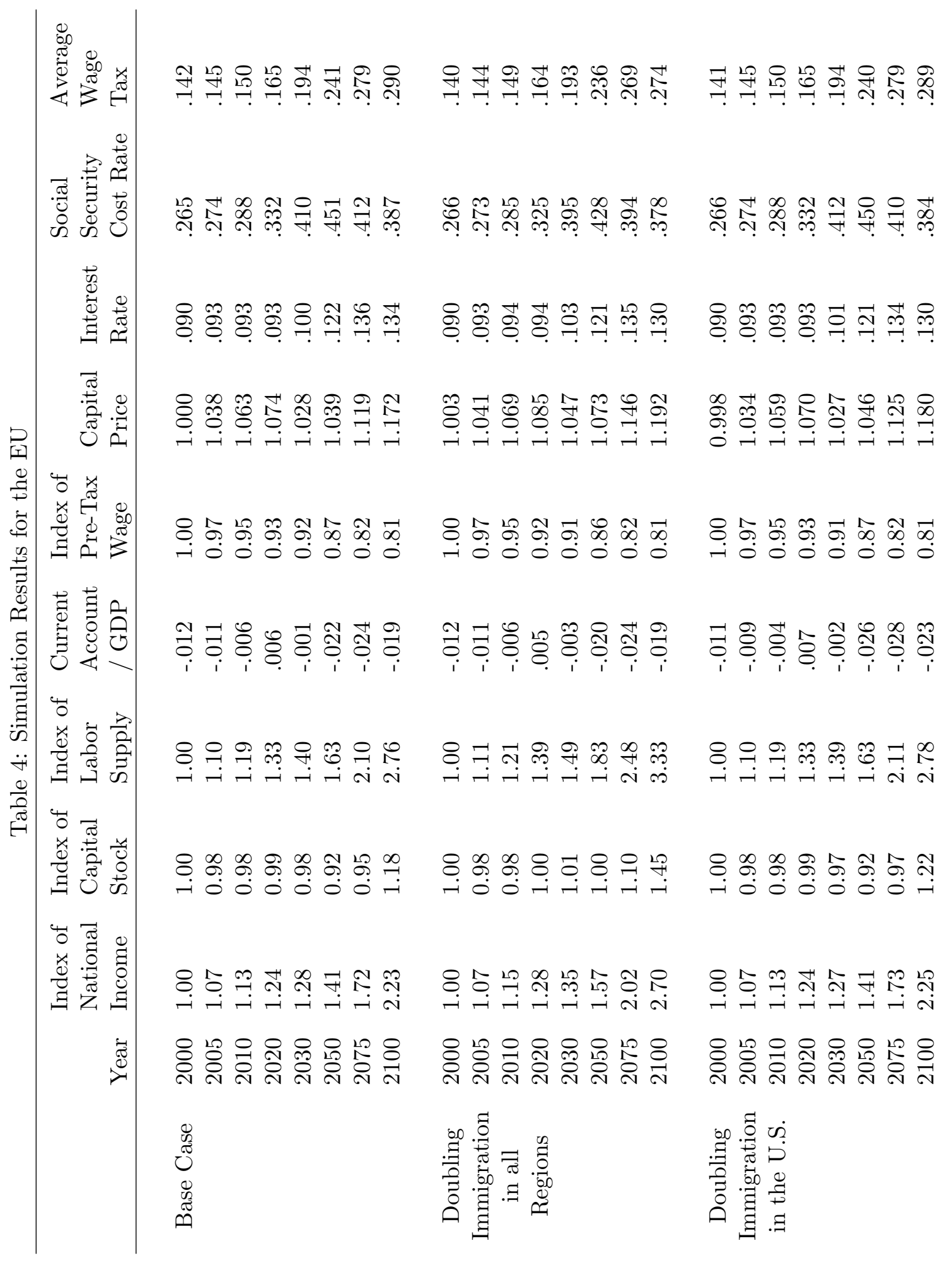




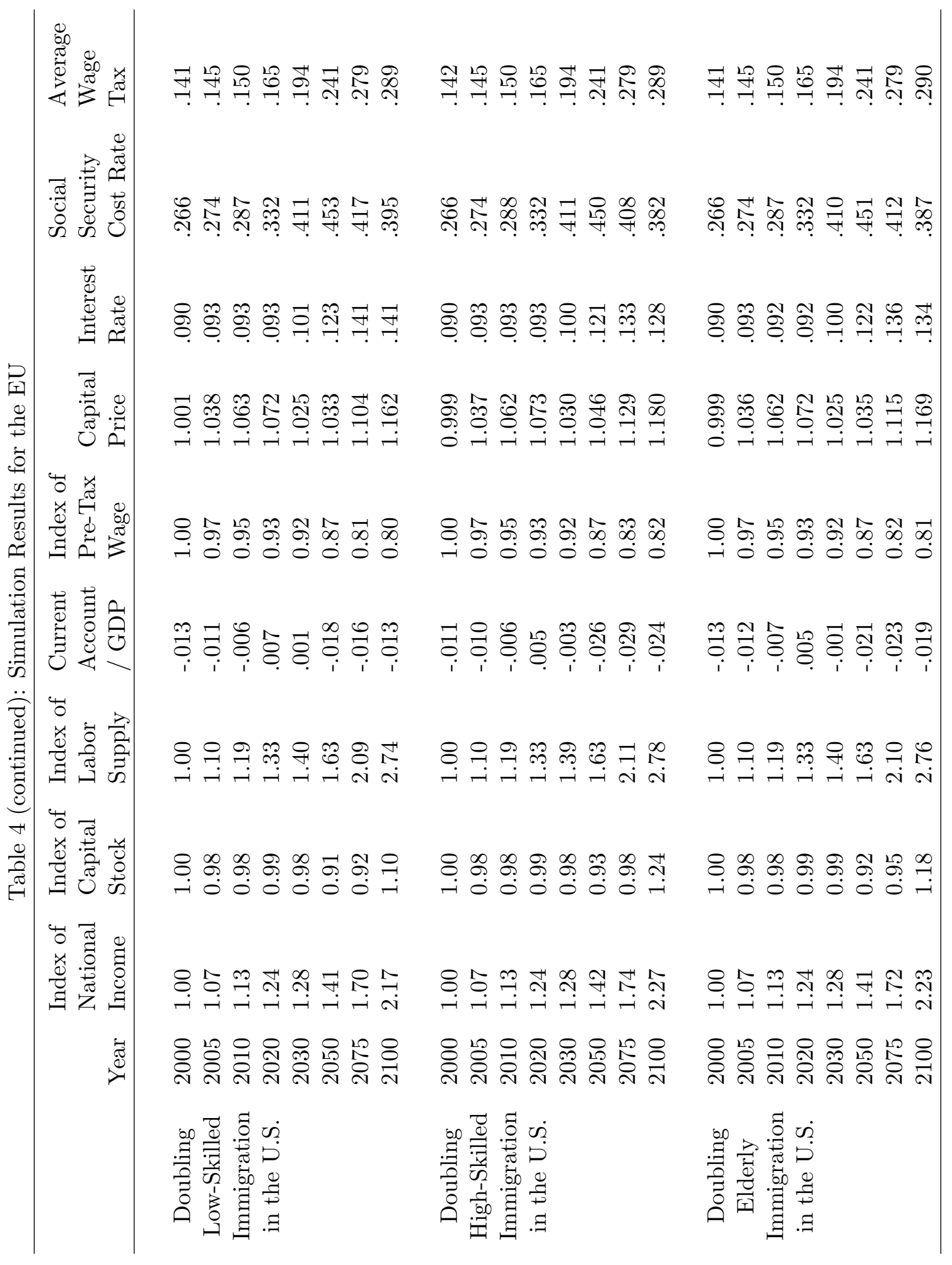




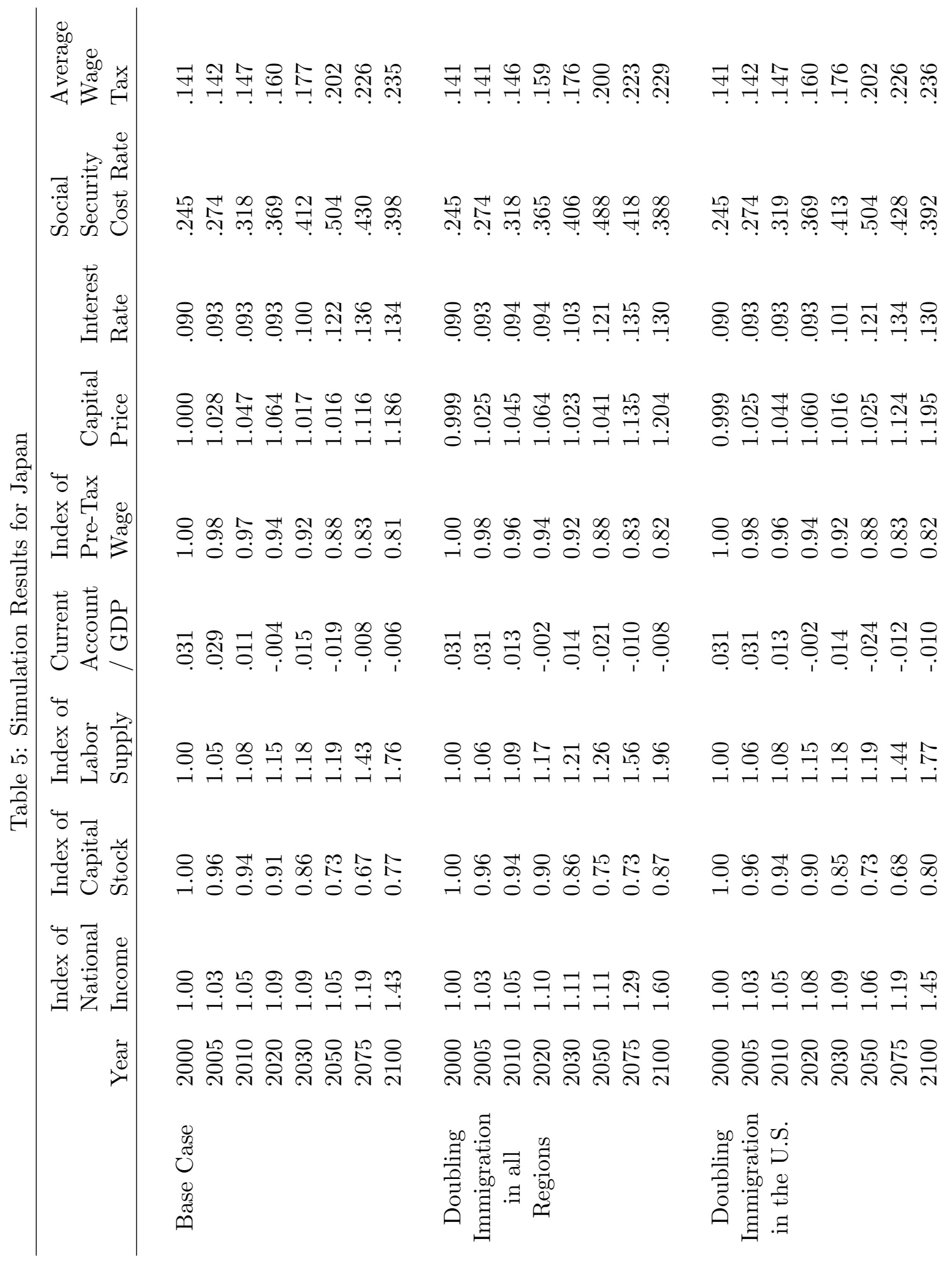




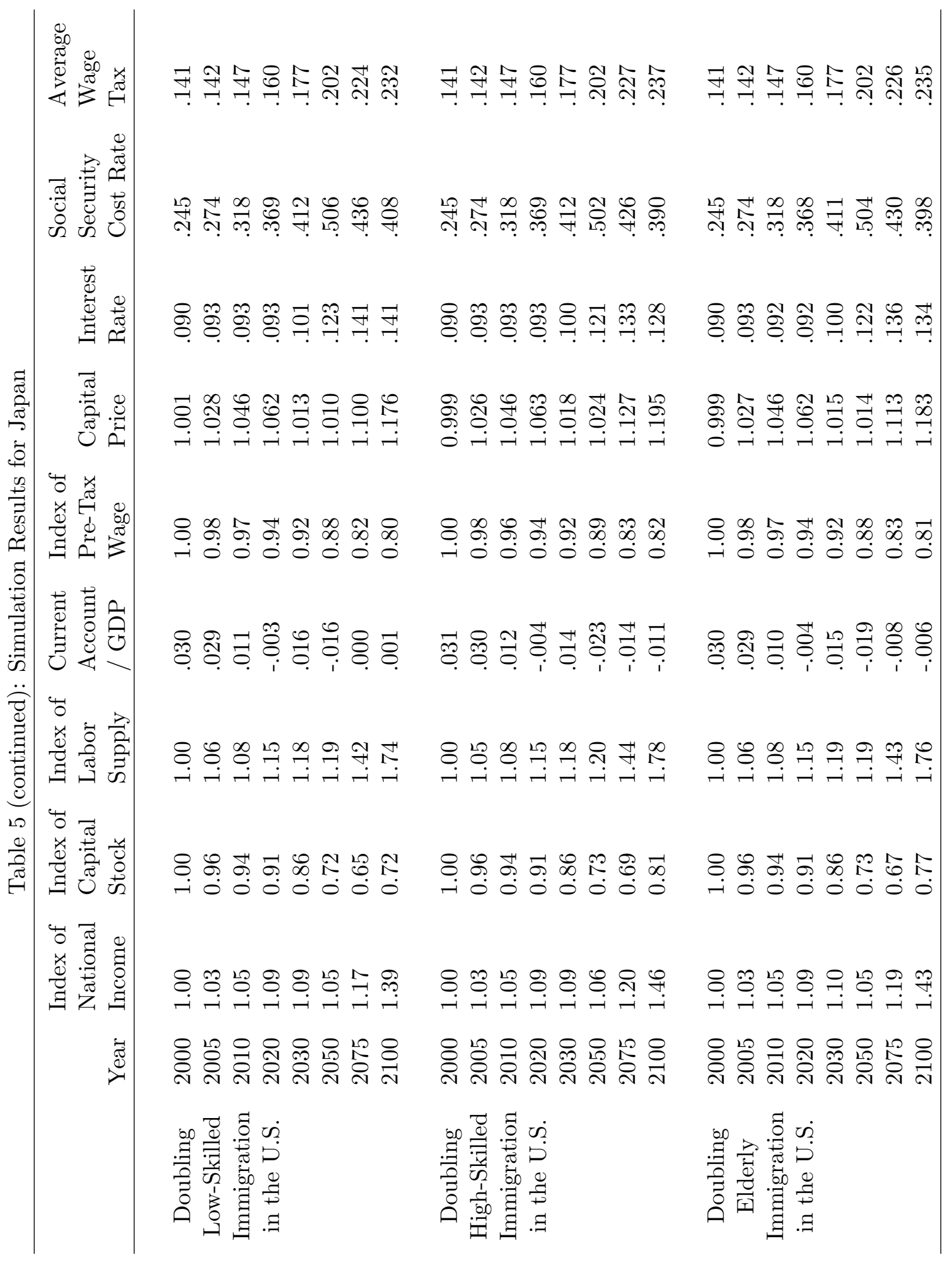


Table 6: Welfare Effects of Doubling Immigration in all Regions

\begin{tabular}{r|rrr|rrr|rrrr}
\hline & \multicolumn{3}{|c|}{ USA } & \multicolumn{4}{c|}{ EU } & \multicolumn{4}{c}{ Japan } \\
& \multicolumn{3}{|c}{ Income class } & \multicolumn{3}{c}{ Income class } & \multicolumn{3}{c}{ Income class } \\
Birth year & 1 & 2 & 3 & 1 & 2 & 3 & 1 & 2 & 3 \\
\hline 1910 & 0.15 & 0.12 & 0.10 & 0.20 & 0.11 & 0.04 & 0.22 & 0.09 & 0.02 \\
1920 & 0.18 & 0.14 & 0.08 & 0.12 & 0.09 & 0.08 & 0.16 & 0.11 & 0.09 \\
1930 & 0.23 & 0.19 & 0.11 & 0.16 & 0.12 & 0.11 & 0.24 & 0.17 & 0.10 \\
1940 & 0.27 & 0.23 & 0.17 & 0.25 & 0.20 & 0.13 & 0.27 & 0.22 & 0.17 \\
1950 & 0.14 & 0.19 & 0.18 & 0.24 & 0.23 & 0.18 & 0.23 & 0.22 & 0.19 \\
1960 & -0.21 & -0.02 & 0.10 & 0.07 & 0.15 & 0.17 & 0.06 & 0.14 & 0.17 \\
1970 & 0.01 & 0.09 & 0.11 & 0.16 & 0.21 & 0.16 & 0.07 & 0.14 & 0.15 \\
1980 & 0.38 & 0.31 & 0.13 & 0.54 & 0.45 & 0.15 & 0.20 & 0.21 & 0.11 \\
1990 & 0.53 & 0.43 & 0.10 & 1.30 & 1.04 & 0.20 & 0.52 & 0.45 & 0.12 \\
2000 & 0.97 & 0.78 & 0.22 & 2.64 & 2.17 & 0.35 & 1.08 & 0.89 & 0.13 \\
2010 & 1.18 & 0.93 & 0.27 & 4.44 & 3.83 & 0.63 & 1.93 & 1.64 & 0.16 \\
2020 & 1.17 & 0.90 & 0.22 & 5.42 & 4.74 & 0.86 & 2.94 & 2.57 & 0.21 \\
2030 & 1.58 & 1.16 & 0.34 & 5.85 & 5.06 & 1.10 & 3.40 & 2.95 & 0.30 \\
\hline
\end{tabular}

Table 7: Welfare Effects of Doubling Immigration in the U.S.

\begin{tabular}{r|rrr|rrr|rrrr}
\hline & \multicolumn{3}{|c|}{ USA } & \multicolumn{4}{c|}{ EU } & \multicolumn{4}{c}{ Japan } \\
& \multicolumn{3}{|c}{ Income class } & \multicolumn{3}{c}{ Income class } & \multicolumn{3}{c}{ Income class } \\
Birth year & 1 & 2 & 3 & 1 & 2 & 3 & 1 & 2 & 3 \\
\hline 1910 & 0.11 & 0.10 & 0.07 & 0.15 & 0.09 & 0.03 & 0.17 & 0.08 & 0.02 \\
1920 & 0.12 & 0.10 & 0.05 & 0.09 & 0.07 & 0.06 & 0.11 & 0.08 & 0.06 \\
1930 & 0.14 & 0.12 & 0.07 & 0.10 & 0.08 & 0.07 & 0.15 & 0.10 & 0.06 \\
1940 & 0.16 & 0.14 & 0.09 & 0.15 & 0.12 & 0.08 & 0.16 & 0.13 & 0.11 \\
1950 & 0.05 & 0.09 & 0.09 & 0.14 & 0.14 & 0.11 & 0.13 & 0.13 & 0.11 \\
1960 & -0.24 & -0.09 & 0.02 & 0.07 & 0.10 & 0.11 & 0.05 & 0.09 & 0.10 \\
1970 & 0.04 & 0.07 & 0.04 & 0.02 & 0.06 & 0.09 & -0.01 & 0.04 & 0.08 \\
1980 & 0.42 & 0.31 & 0.09 & -0.02 & 0.02 & 0.05 & -0.03 & 0.00 & 0.05 \\
1990 & 0.61 & 0.46 & 0.08 & -0.04 & -0.01 & 0.04 & -0.09 & -0.05 & 0.03 \\
2000 & 1.07 & 0.84 & 0.22 & -0.08 & -0.06 & 0.02 & -0.14 & -0.11 & 0.00 \\
2010 & 1.27 & 1.01 & 0.29 & -0.05 & -0.07 & -0.02 & -0.15 & -0.16 & -0.05 \\
2020 & 1.25 & 0.97 & 0.26 & 0.19 & 0.12 & -0.05 & 0.06 & 0.00 & -0.11 \\
2030 & 1.62 & 1.20 & 0.36 & 0.45 & 0.33 & -0.07 & 0.36 & 0.24 & -0.14 \\
\hline
\end{tabular}


Table 8: Welfare Effects of Doubling Low-Skilled Immigration in the U.S.

\begin{tabular}{r|rrr|rrr|rrrr}
\hline & \multicolumn{3}{|c|}{ USA } & \multicolumn{4}{c|}{ EU } & \multicolumn{4}{c}{ Japan } \\
& \multicolumn{3}{|c}{ Income class } & \multicolumn{3}{c}{ Income class } & \multicolumn{3}{c}{ Income class } \\
Birth year & 1 & 2 & 3 & 1 & 2 & 3 & 1 & 2 & 3 \\
\hline 1910 & 0.17 & 0.11 & 0.03 & 0.12 & 0.07 & 0.02 & 0.13 & 0.06 & 0.02 \\
1920 & 0.14 & 0.08 & 0.01 & 0.05 & 0.03 & 0.03 & 0.06 & 0.05 & 0.04 \\
1930 & 0.13 & 0.07 & 0.01 & 0.03 & 0.02 & 0.03 & 0.05 & 0.04 & 0.03 \\
1940 & 0.08 & 0.05 & 0.01 & 0.03 & 0.02 & 0.02 & 0.04 & 0.03 & 0.04 \\
1950 & -0.41 & -0.05 & 0.01 & 0.06 & 0.04 & 0.03 & 0.04 & 0.03 & 0.03 \\
1960 & -1.46 & -0.21 & -0.02 & 0.06 & 0.05 & 0.04 & 0.04 & 0.04 & 0.03 \\
1970 & -0.85 & -0.48 & -0.14 & 0.04 & 0.04 & 0.03 & 0.02 & 0.02 & 0.03 \\
1980 & -0.32 & -0.80 & -0.30 & 0.01 & 0.02 & 0.03 & -0.01 & 0.01 & 0.02 \\
1990 & -1.54 & -1.60 & -0.61 & -0.01 & 0.02 & 0.04 & -0.03 & 0.01 & 0.04 \\
2000 & -2.71 & -2.61 & -0.99 & -0.08 & -0.02 & 0.07 & -0.08 & -0.01 & 0.08 \\
2010 & -4.30 & -3.79 & -1.44 & -0.26 & -0.14 & 0.11 & -0.24 & -0.11 & 0.13 \\
2020 & -6.04 & -5.20 & -2.05 & -0.49 & -0.31 & 0.16 & -0.51 & -0.31 & 0.20 \\
2030 & -7.03 & -6.68 & -2.67 & -0.78 & -0.52 & 0.22 & -0.82 & -0.54 & 0.30 \\
\hline
\end{tabular}

Table 9: Welfare Effects of Doubling High-Skilled Immigration in the U.S.

\begin{tabular}{r|rrr|rrr|rrrr}
\hline & \multicolumn{4}{|c|}{ USA } & \multicolumn{3}{c|}{ EU } & \multicolumn{4}{c}{ Japan } \\
Birth year & \multicolumn{3}{|c}{ Income class } & \multicolumn{3}{c}{ Income class } & \multicolumn{3}{c}{ Income class } \\
\hline 1910 & 0.01 & 0.01 & 0.02 & 0.03 & 0.02 & 0.01 & 0.04 & 0.02 & 0.00 \\
1920 & 0.02 & 0.01 & 0.02 & 0.02 & 0.02 & 0.01 & 0.03 & 0.02 & 0.02 \\
1930 & 0.02 & 0.02 & 0.02 & 0.03 & 0.02 & 0.02 & 0.04 & 0.03 & 0.02 \\
1940 & 0.04 & 0.03 & 0.03 & 0.04 & 0.03 & 0.02 & 0.04 & 0.04 & 0.03 \\
1950 & 0.09 & 0.06 & 0.01 & 0.04 & 0.03 & 0.03 & 0.03 & 0.03 & 0.03 \\
1960 & 0.16 & 0.11 & -0.06 & 0.02 & 0.02 & 0.02 & 0.01 & 0.02 & 0.02 \\
1970 & 0.28 & 0.20 & 0.02 & 0.01 & 0.01 & 0.02 & 0.00 & 0.01 & 0.01 \\
1980 & 0.44 & 0.32 & 0.15 & 0.01 & 0.00 & 0.00 & 0.00 & 0.00 & 0.00 \\
1990 & 0.88 & 0.66 & 0.23 & 0.02 & 0.00 & -0.02 & 0.01 & -0.01 & -0.02 \\
2000 & 1.51 & 1.14 & 0.45 & 0.07 & 0.02 & -0.05 & 0.04 & -0.01 & -0.06 \\
2010 & 2.17 & 1.64 & 0.64 & 0.21 & 0.11 & -0.09 & 0.16 & 0.05 & -0.12 \\
2020 & 2.84 & 2.14 & 0.85 & 0.47 & 0.31 & -0.13 & 0.44 & 0.26 & -0.18 \\
2030 & 3.53 & 2.65 & 1.19 & 0.77 & 0.54 & -0.16 & 0.78 & 0.53 & -0.23 \\
\hline
\end{tabular}


Table 10: Welfare Effects of Doubling Elderly Immigration in the U.S.

\begin{tabular}{r|rrr|rrr|rrrr}
\hline & \multicolumn{3}{|c|}{ USA } & \multicolumn{4}{c|}{ EU } & \multicolumn{4}{c}{ Japan } \\
& \multicolumn{3}{|c|}{ Income class } & \multicolumn{3}{c|}{ Income class } & \multicolumn{3}{c}{ Income class } \\
Birth year & 1 & 2 & 3 & 1 & 2 & 3 & 1 & 2 & 3 \\
\hline 1910 & 0.03 & 0.03 & 0.02 & 0.04 & 0.03 & 0.01 & 0.05 & 0.02 & 0.01 \\
1920 & 0.02 & 0.02 & 0.01 & 0.01 & 0.01 & 0.01 & 0.02 & 0.02 & 0.01 \\
1930 & 0.01 & 0.01 & 0.01 & 0.00 & 0.00 & 0.01 & 0.01 & 0.01 & 0.01 \\
1940 & 0.00 & 0.00 & 0.00 & -0.01 & -0.01 & 0.00 & -0.01 & -0.01 & 0.00 \\
1950 & 0.00 & -0.01 & -0.01 & 0.00 & 0.00 & -0.01 & 0.00 & -0.01 & -0.01 \\
1960 & 0.00 & -0.01 & -0.01 & 0.03 & 0.01 & -0.01 & 0.03 & 0.01 & -0.01 \\
1970 & -0.01 & -0.02 & 0.00 & 0.04 & 0.02 & -0.01 & 0.03 & 0.01 & -0.01 \\
1980 & -0.06 & -0.05 & -0.01 & 0.03 & 0.01 & -0.01 & 0.02 & 0.00 & -0.01 \\
1990 & -0.18 & -0.13 & -0.03 & 0.04 & 0.02 & -0.01 & 0.04 & 0.02 & -0.01 \\
2000 & -0.31 & -0.24 & -0.07 & 0.06 & 0.04 & -0.01 & 0.06 & 0.05 & -0.01 \\
2010 & -0.39 & -0.31 & -0.10 & 0.06 & 0.05 & 0.00 & 0.07 & 0.06 & 0.00 \\
2020 & -0.43 & -0.34 & -0.12 & 0.03 & 0.02 & 0.00 & 0.06 & 0.04 & 0.00 \\
2030 & -0.44 & -0.35 & -0.13 & 0.02 & 0.01 & 0.00 & 0.04 & 0.03 & 0.00 \\
\hline
\end{tabular}

